\title{
Standard Arabic [q]-Lexical-Borrowings in the Speech of Syrian Rural Migrants
}

\section{Rania Habib*}

\begin{abstract}
This study examines lexical borrowings from Standard Arabic containing the voiceless uvular stop [q] sound in the speech of 52 Christian rural migrant speakers to the city of Hims in Syria. The study shows that both older and younger males use more lexical borrowings than older and younger females respectively. This gender difference is attributed to the different gender roles and expectations of males and females in society and consequently the gender identity projected by the use of more or less lexical borrowings. Age does not play a role in the use of lexical borrowings, although younger speakers are generally more educated than older speakers and education plays some role. Those at the top of the education scale, i.e. holding professional degrees such as medicine, dentistry, and master's degrees, show higher use of lexical borrowings than speakers with bachelor's degrees and lower levels of education. The difference is statistically significant between speakers with professional degrees, on the one hand, and those with bachelor's degrees, associate degrees and elementary school education, on the other. This difference is not statistically significant with speakers with middle and high school education. Interestingly, education overrides the gender effect when females are at the top of the education scale. That is, females who are highly educated tend to use lexical borrowings as much as males of the same educational level. In this sense, lexical borrowing becomes a marker of higher education not only among males, but also among females. In other words, the gender identity differentiation diminishes when speakers are highly educated.
\end{abstract}

Keywords. lexical borrowings; Syrian Arabic; rural migrants; urban centers; education; gender; age

1. Introduction. Lexical borrowing is the process of adopting one word or more from another language or dialect. For example, the words mafia and paparazzi were adopted in English from Italian (Daulton 2012:3310). Lexical borrowing has been defined and examined by numerous researchers (e.g. Poplack, Sankoff \& Miller 1988) in terms of what it means (e.g. Poplack 1997:305), which words or speech parts are borrowed most (e.g. Haugen 1950, Weinreich 1974, Bowden 2005), and whether these terms are assimilated into the phonology, morphology, or syntax of the matrix or native language (Boyd, Andersson \& Thornell 1997, Haspelmath 2009). However, there is scant work on the use of lexical borrowings based on social factors such as gender, education, and age particularly in the Arab world. Hence, this study seeks to unfold such use in the speech of 52 Christian rural migrant speakers to the city of Hims in Syria. In this study, lexical borrowing refers to borrowing words containing the voiceless uvular stop [q] from Standard Arabic (SA) into the colloquial speech (CS) of Syrian rural migrants. In order to understand this phenomenon, I will provide a brief description of the language/dialect situation of these rural migrants. The variable (q) is realized in SA as [q] with the underlying form /q/. It is realized in colloquial Himsi Arabic as the glottal stop [?] with the assumed underlying form / ?/ (Daher 1998) and in the speech of rural migrant speakers as either [q], the traditional rural form,

\footnotetext{
* Author: Rania Habib, Syracuse University (rhabib@syr.edu).
} 
or [?] the Himsi urban form. For examples, the SA word [qaSad] 'sat down' will be pronounced in Himsi Arabic as [PaSad] and a variation of the two forms in the speech of rural migrants. Put differently, the corresponding sound of the SA [q] in the city of Hims is [?], excluding lexical borrowings from SA that retain the [q] sound in the speech of both local Himsi speakers and highly assimilated rural migrants to the Himsi dialect. Many rural migrants who come from rural areas that traditionally use [q] in their speech and particularly the younger generation show a prominent shift towards the use of the urban form [?] to fit in and sound more urbane and prestigious (Habib 2005, 2008, 2010). Nonetheless, these migrant speakers behave like Himsi speakers regarding the use of SA borrowings with the [q] sound, including older speakers who predominantly retain the rural form [q]. It is worth noting that SA maintains a very high status in Syria and other Arab countries due to its religious importance as the language of the Qur'an and its use in formal settings, education, and the media.

The interest in discovering if the social factors gender, age, and education influence the frequency of use of SA lexical borrowings with [q] pose the following research questions:

(1) Do rural migrant males and females, older and younger rural migrants, or highly educated and less educated rural migrants differ in their use of lexical borrowings?

(2) What are the implications of such differences if they exist?

2. Rural migrants in the city of Hims. The rural migrants in this study come from a number of neighboring villages in the central western part of Syria, mainly from a collection of Christian villages called Wadi Al-Nasara 'the valley of the Christians'. This collection of villages are central to three major urban centers, Hims, Hamah, and Tartous. However, most of them are administratively within Hims Governorate of which the city of Hims is the capital. Most of these rural migrants migrated to the city of Hims to seek better life style, education, and better jobs. Hims is particularly chosen not only for its closeness to their villages, but also due to being the hub for the third largest public university in the country. Hence, there is a great emphasis among the older generation participants on giving their children the best education possible. The strong value attached to education is instilled in their children from a very young age.

In the city of Hims, rural migrants feel a little alienated due to the superior attitudes of Himsis towards peasants, assuming that every rural migrant is a farmer. For this reason, most rural migrants, and particularly Christians who come from more developed and advanced villages, try to integrate into the urban fabric by accommodating to the Himsi dialect. Consequently, among the younger generation of migrants, one can observe a complete shift from the rural [q] to the urban [?] (Habib 2010). They also try to override this superior attitude by becoming highly educated and securing respectable jobs. It is worth noting that despite the linguistic accommodation and the high educational and job achievements, there continues to be some feeling of inferiority among some migrants due to some derogatory terms used by some Himsis on occasions, such as fallah 'peasant'.

3. Background. Many researchers have defined borrowing in similar terms. For example, Poplack (1997:305) defines it as the “incorporation of foreign features into a group's native language by speakers of that language. The native language is maintained, but is changed by the addition of the incorporated features.” Similarly, Mesthrie and Leap (2000:245) define borrowing as "a technical term for the incorporation of an item from one language into another. These items could be (in terms of decreasing order of frequency) words, grammatical elements 
or sounds”. For example, African languages have assimilated from English a great number of terms associated with "Christianity, technology and modernity" (Mesthrie \& Leap 2000:250). In other words, borrowing is considered "an adaptive strategy undertaken by speakers to enrich certain registers of a language, rather than having to switch to the new language for that register" (Mesthrie \& Leap 2000:245). However, borrowing is not limited to borrowing from one language to another; rather, it could be borrowing from one dialect to another within the same language (Haugen \& Mithun 2003:244, Daulton 2012:3308). The latter describes the situation of borrowing from SA into CS. Based on the given definitions, borrowing from SA could be considered a kind of enrichment to CS without switching completely to SA. Borrowing from SA into CS is not surprising given the constant contact between SA and CS, as most researchers agree that borrowing is the result of language contact particularly longer, older, and more established contact (e.g. Boyd et al. 1997, Poplack 1997, Bowden 2005).

What can be borrowed from one language or dialect into another may be diverse. However, borrowing lexemes seems to occur before borrowing non-lexical features such as morphological, phonological and syntactic structures (Haugen \& Mithun 2003:246). Arabic is similar in this regard as Palva (1969:40) indicates "A great majority of the classicism in the 'elevated' colloquial are lexical, or at least indirectly due to lexical loans. This is only natural, because modern concepts usually have no equivalents in the dialect but must be borrowed from literary language." Lexical borrowing in Arabic mainly refer to borrowing from the lexicon of SA into CS and has been described with terms such as "borrowing" (Garbell 1958), "classicism" (Ferguson 1959, Blanc 1964), and "literary borrowing" (Al-Ani 1976). It is believed that borrowing between SA and CS is "a one-way process" (Daher 1998:75-76). That is, only CS borrows words and phrases from SA, not vice versa. This phenomenon is attributed to "lexical suppletion” (Blanc 1964) and necessity (Diem 1974:26, Owens \& Bani-Yasin 1991:25), implying the use or borrowing of vocabulary from SA because they are lacking in CS, e.g. taqaddom 'progress' where there is no *taqaddom in CS. The influence of SA and the interference of "classical words and expressions" is most observed in the speech of educated speakers because SA "is propagated more and more in the Arab world through education and the media" and "because of the inadequacy of the dialect, an educated speaker, may, in certain circumstances, have to resort to higher language varieties, thereby using a non-normated mixed language” (Mol 2003:78). For example, Owens and Bani-Yasin (1991) provide borrowed lexical examples that started to be used with the opening of the Yarmouk University in Jordan in 1976, e.g. masa:q 'course' and qa:\{a 'classroom'. With frequent use and time, such borrowed words become part of the dialects (Diem 1974, Abu-Haidar 1992:104, Wilmsen 1995). For instance in Baghdad, words such as musaqqaf 'educated' and taqaddom 'progress' have been assimilated into the everyday speech of Baghdadis (Abu-Haidar 1992:104).

Regarding the (q) variable, most Arab researchers agree that the occurrence of $[q]$ in the speech of Arabs where [?], [g], or [k] is the norm is due to lexical borrowing from SA (e.g. AlAni 1976, Abdel-Jawad 1981:216, Haeri 1991:147, Daher 1998:191). This borrowing is suggested to be, although actual statistics are not provided, the result of increased education and adoption from literary Arabic (Garbell 1958:303, Al-Ani 1976:106, Haeri 1991). Al-Ani (1976:107-108) divided lexical borrowings into two groups:

a. Items that are borrowed with their literary unchanged morphological form, e.g. verses from the Qur'an, sayings, etc.: e.g. qiya:ma 'resurrection'. 
b. Items in which the morphological form changed to fit the morphology of the dialect: e.g. fo:q 'longing'. In SA, this word is pronounced fau:q. However, some items that are pronounced interchangeably as [q] or [g] in Iraqi Arabic, e.g. Jaqq/Jagg 'tear, split off', may still be in the process of integrating fully, including phonologically, into the dialect.

Daher (1998:148-149) also showed that proper names such as dimafq 'Damascus' and lexical items such as saqa:fa 'education, culture' retain their SA [q]. In addition, where there are lexical doublets or homophones, such as qa:nu:n "law, statute” and ?a:nu:n (SA qa:nu:n) 'musical instrument', the former retains its SA [q] to distinguish it from the latter. This choice might be due to attributing the first meaning of the doublet to being a more technical or specialized word. It is widely accepted that erudite and technical domains such as science, medicine, politics, law, economics, etc. use jargons and technical terms that are borrowed from SA into CS (Holes 1995, Daher 1998:78). Daher (1998) also indicated that the existence of / $/$ / in a word that must be realized as [?] leads to the realization of (q) as [q], i.e. the retention of the SA [q] in a word, e.g. /Paqall/ 'less' is realized as [?aqall] due to the presence of [?] in the word. However, in the current data, words such as / Paqall/ are realized as both [?aqall] and [?aPall], indicating that such words are assimilating into the phonology of the dialect. However, Daher (1998:106) recognizes that integration of borrowed words from SA in Damascene Arabic (DA) occurs. He even uses the term "hybridization" to describe this integration phenomenon, such as the use of the DA mood marker $b(i)$ - as a prefix to SA verbs. For Daher (1998:184), first, "many such items have by now been incorporated into DA to the point where speakers have begun to replace the [SA] [q] with [?]" and second, "as speakers have become accustomed to hearing and using [q], [q] has begun to be generalized to other lexical items that were long used in DA with only the [?]”.The first observation is found in the present data, particularly in the speech of local Himsi speakers, where some SA words are phonologically integrated into their speech by replacing the SA [q] with the Himsi form [?], e.g. the use of [ta?li:diyyi] instead of [taqli:diyyi] 'traditional' (Habib 2005:39); [t?ayyem] instead of [tqayyem] 'evaluate'; [?adi:ra] instead of [qadi:ra] 'capable (F)'. These examples are taken from the speech of a 40-year-old local Himsi female speaker. However, the generalization of $[\mathrm{q}]$ to other lexical items is rarely found in the current data. There are terms that are still oscillating between SA [q] and urban [?] in the speech of rural migrants, e.g. [ $\mathrm{t}^{\mathrm{f}}$ abaqa]

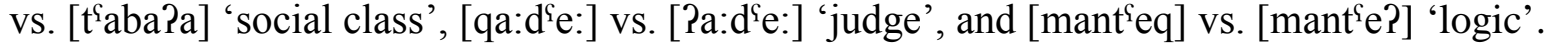
Such examples indicate that some SA words are in the process of assimilating to the phonological system of CS, but the final outcome and the time required to complete such assimilation are still ambiguous and require further investigation.

4. Methods and data. The lexical borrowings in this study are extracted from the naturally occurring speech of 52 Christian rural migrant speakers to the city of Hims in Syria. The data were collected over two summers in 2004 and 2006. Each speaker was recorded for 30-45 minutes. As an in-group member, the researcher led unstructured conversations with the participants in the presence of other family members and/or friends who occasionally contributed to the conversations, making them more natural (for full description of data collection and data set including other social factors, see Habib 2008, 2010). The speakers are almost equally divided into males (24) and females (28) and two age groups: younger and older. The younger age group consists of 24 speakers (11 males and 13 females) whose ages range from 16 to 35 years old; the older age group consists of 28 speakers (13 males and 15 females) whose ages are $52+$ years old. Each age group also includes almost equal number of males and females. Education is divided into six levels: elementary school (ES) consisting of 4 speakers, middle 
school (MS) consisting of 8 speakers, high school (HS) consisting of 9 speakers, associate degree (A.A.) consisting of 9 speakers, bachelor's degree (B.A.) consisting of 16 speakers, and professional (doctors, dentists, holders of a master's degree) consisting of 6 speakers.

Professional refers to those who have studied more than 5 years in college. Table 1 represents the linguistic distribution of the colloquial realizations, [q] and [?], of the variable (q) and SA lexical borrowings with [q] in the speech of the 52 speakers according to gender and age and Table 2 according to education.

\begin{tabular}{llllllll}
\hline Speaker & $\begin{array}{l}\text { Lexical } \\
\text { borrowings } \\
\text { with [q] }\end{array}$ & $\begin{array}{l}\text { \% of Lexical } \\
\text { borrowings } \\
\text { with [q] }\end{array}$ & $\begin{array}{l}\text { No. } \\
\text { of [q] }\end{array}$ & $\begin{array}{l}\text { \% of } \\
\text { [q] }\end{array}$ & $\begin{array}{l}\text { No. } \\
\text { of [?] }\end{array}$ & $\begin{array}{l}\text { \% of } \\
\text { [?] }\end{array}$ & $\begin{array}{l}\text { Total of (q) and } \\
\text { Lexical borrowings } \\
\text { with [q] }\end{array}$ \\
\hline 13 Older males & 391 & 12 & 2715 & 84 & 145 & 4 & 3251 \\
15 Older females & 176 & 6 & 2168 & 71 & 714 & 23 & 3058 \\
11 Younger males & 361 & 13 & 805 & 28 & 1686 & 59 & 2852 \\
13 Younger females & 195 & 6 & 18 & 0 & 3141 & 94 & 3354 \\
$\begin{array}{l}\text { Total for all } \\
\text { speakers }\end{array}$ & 1123 & 9 & 5708 & 46 & 5686 & 45 & 12517 \\
\hline
\end{tabular}

Table 1. Linguistic distribution of the variable $(q)$ including the colloquial realizations [q] and [?] and the SA lexical borrowings with [q] according to age and gender.

\begin{tabular}{llllllll}
\hline Education group & $\begin{array}{l}\text { Lexical } \\
\text { borrowings } \\
\text { with [q] }\end{array}$ & $\begin{array}{l}\text { \% of Lexical } \\
\text { borrowings } \\
\text { with [q] }\end{array}$ & $\begin{array}{l}\text { No. } \\
\text { of [q] }\end{array}$ & $\begin{array}{l}\text { \%of of } \\
\text { [q] }\end{array}$ & $\begin{array}{l}\text { No. } \\
\text { of [?] }\end{array}$ & $\begin{array}{l}\text { \% of } \\
\text { [?] }\end{array}$ & $\begin{array}{l}\text { Total of (q) and } \\
\text { Lexical borrowings } \\
\text { with [q] }\end{array}$ \\
\hline 6 Professional speakers & 235 & 17 & 251 & 18 & 904 & 65 & 1390 \\
\hline 16 B.A. speakers & 325 & 8 & 890 & 22 & 2892 & 70 & 4107 \\
\hline 9 A.A. speakers & 173 & 8 & 756 & 36 & 1153 & 56 & 2082 \\
\hline 9 HS speakers & 194 & 10 & 1060 & 58 & 584 & 32 & 1838 \\
\hline 8 MS speakers & 177 & 7 & 2111 & 87 & 130 & 6 & 2418 \\
\hline 4 ES speakers & 19 & 3 & 638 & 94 & 23 & 3 & 680 \\
\hline
\end{tabular}

Table 2. Linguistic distribution of the variable (q) including the colloquial realizations [q] and [?] and the SA lexical borrowings with [q] by the various education groups.

Because the interview time slightly differs for each speaker and the topics of the conversations greatly differ among speakers, the use of lexical borrowings is calculated for each speaker as a percentage of his/her total use of the sounds [q] and [?] as realizations of the variable (q) and [q] as realization of the SA lexical borrowings with /q/ (Tables 1 \& 2). Comparisons between males and females, the younger and older generations, and the six educational levels in the use of lexical borrowings are done to see if any of the social factors gender, age, and education affect the degree of use of lexical borrowings.

In addition to comparing the counts and percentages of the use of lexical borrowings with [q] by each social category or level (Tables 1 \& 2), three separate one-way ANOVA tests were run using raw (i.e. count) data to determine if there were significant associations between the use of lexical borrowings and each of the social factors: gender, age, and education. Prior to running the one-way ANOVA tests, the normality of distributions of the variables were assessed using boxplots and Shapiro-Wilk normality tests to determine the use of the most appropriate quantitative models and statistics for the data. 
5. Results and findings. Table 1 shows that the total number of lexical borrowings in the speech of the 52 speakers is 1123, which constitutes $9 \%$ of the total use of the sounds [q] and [?] as realizations of the variable (q) and [q] as the realization of the SA lexical borrowings with /q/. This number of lexical borrowings indicates that the average use of lexical borrowing per speaker should be approximately 22 lexical items and 18 according to the standard deviation (18.24) and the median (18). However, this is not the case. There are speakers who did not use any lexical borrowing (e.g. Speaker \# 43) and others like Speaker \# 9 who used 72 tokens of lexical borrowings accounting for $36 \%$ of his total use of [q] and [?] including lexical borrowings. Such discrepancy in the use of lexical borrowings prompted the comparisons based on gender, age, and education to see if the observed differences are driven by these social factors.

Cross-tabulation of gender and age when lexical borrowings are isolated from the rest of the data revealed that both younger (65\%) and older (69\%) males use more lexical borrowings than younger (35\%) and older (31\%) females respectively. Thus, there are no important differences between younger and older males or younger and older females. There is mainly a gender difference, not an age difference. Furthermore, examining the use of lexical borrowings in isolation of the rest of the data by the different education group revealed that highly educated speakers use many more lexical borrowings than other speakers: those with B.A. education at $29 \%$ and professionals at $21 \%$. The least use of lexical borrowing is seen in those who have only ES education at $2 \%$. The other three levels (MS, HS, and A.A.) of education fall in the middle between the highly and least educated, ranging in their use of lexical borrowings from $15 \%$ to17\%. All four speakers who have only ES education use a total of 19 lexical items which is lower than the average for one speaker, i.e. about 5 lexical items per speaker. Each of the eight speakers with MS education use approximately 22 lexical items, which is equal to the average. Similarly, each of the nine speakers with HS education use approximately 22 lexical items, which is equal to the average. Each of the nine speakers with A.A. education use approximately 19 lexical items, which is slightly lower than the average. Each of the sixteen speakers with B.A. education use approximately 20 lexical items, which is slightly lower than the average. Each of the six speakers with professional education use approximately 39 lexical items, which is much higher than the average. However, because the number of speakers in each education level is different, individual comparisons among speakers of each level is done and is measured in relation to the total use of the sounds [q] and [?] as realizations of the variable (q) and [q] as the realization of the SA lexical borrowings with /q/, as in Table 3. Then, the percentage of each education level is compared to the percentages of the other levels, as in Table 2. The same method is applied for comparing males and females and older and younger speakers for the same reason: each group may have a slightly different number of speakers (Table 1).

5.1. COMPARISON BY GENDER AND AGE AGAINST THE REST OF THE DATA. Table 1 shows that older males use double the lexical borrowings used by older females (12\% vs. $6 \%$ respectively). Amazingly, the behavior of younger males and females parallels that of older males and females in percentages ( $13 \%$ vs. $6 \%$ respectively), where younger males also use slightly more than double the lexical borrowings used by younger females. Hence, like the comparison of the use of lexical borrowings in isolation of the rest of the data in Section 5, the comparisons when lexical borrowings are measured against the rest of the data show mainly gender difference, i.e. there is no age difference. 
5.2. COMPARISON BY EDUCATION AGAINST THE REST OF THE DATA AND INDIVIDUAL COMPARISONS. Comparing the use of lexical borrowings in each education level based on that level's use of other non-borrowed words with [q] and [?], Table 2 shows that speakers with the highest education level, i.e. professionals, use lexical borrowings at $17 \%$ which is much higher than lower educated speakers (B.A. and A.A. speakers use 8\% and HS and MS speakers use respectively $10 \%$ and $7 \%$ ). Those with ES education use lexical borrowings the least (only 3\%). The difference between speakers with MS, HS, A.A. and B.A. education is minor; their percentages range from $7 \%$ to $10 \%$. Their use of lexical borrowings falls in the middle between highly educated speakers and those with the lowest education level with HS speakers having the highest percentage in the middle (10\%). This could be analogized to Eckert's (1988:206) finding that adolescents are more involved emotionally in adopting an innovation. In her study of the two school groups the burnouts and jocks in the Detroit area, the burnouts emerged as leading in the backing of (e) to $[\Lambda]$. In order for the jocks not to appear conservative, they innovated and adopted a new variant, i.e. the lowering and fronting of (e) to [æ]. The use of these different variants correlated with the two groups' identity and social category, indicating emotional involvement when choosing to use a specific variant. Thus, it is possible that HS speakers use more lexical borrowings, not only due to the topic of conversation, but also to show involvement in well-versed and educated speech.

Although younger speakers are in general more educated than older speakers, they do not necessarily exhibit more lexical borrowings in their speech especially when comparing males to males and females to females. For example, the older male Speakers \# 3 and 9 use respectively 76 (14\%) and 72 (36\%) lexical borrowings, which is comparable to the younger professionally educated male Speakers \# 35 and 39 who use respectively 71 (20\%) and 68 (24\%) lexical borrowings. It is worth noting that all six speakers with professional education are from the younger generation. Five are males and one is female. The professional female (Speaker \# 41) uses as much lexical borrowings (32 tokens, i.e. 19\%) as the professional younger males (Speakers \# 29, 35, 37, 38 \& 39) (Table 3). This means that lexical borrowings become a marker of higher education even among highly educated females, overshadowing the gender difference in the use of lexical borrowings.

\begin{tabular}{llllllll}
\hline \multicolumn{7}{c}{ 6 Professional speakers } \\
\hline Speaker \# & Lexical borrowings with [q] & $\%$ & No. of [q] & $\%$ of [q] & No. of [?] & \% of [?] & Total \\
\hline $29(\mathrm{M})$ & 19 & 7 & 237 & 82 & 32 & 11 & 288 \\
$35(\mathrm{M})$ & 71 & 20 & 0 & 0 & 293 & 80 & 364 \\
$37(\mathrm{M})$ & 33 & 15.5 & 1 & 0.5 & 179 & 84 & 213 \\
$38(\mathrm{M})$ & 12 & 17 & 3 & 4 & 56 & 79 & 71 \\
$39(\mathrm{M})$ & 68 & 24 & 5 & 2 & 212 & 74 & 285 \\
$41(\mathrm{~F})$ & 32 & 19 & 5 & 3 & 132 & 78 & 169 \\
Total & 235 & 17 & 251 & 18 & 904 & 65 & 1390 \\
\hline
\end{tabular}

Table 3. Linguistic distribution of the variable (q) including the colloquial realizations [q] and [?] and the SA lexical borrowings with [q] in the professional education group.

5.3. TESTING FOR SIGNIFICANCE: ONE-WAY ANOVA. Three separate one-way ANOVA tests were run to determine if there were significant differences between males and females, younger and older speakers, and the six education groups in the use of lexical borrowings with [q]. There were a few outliers, as assessed by the boxplots and Shapiro-Wilk normality tests. The use of lexical borrowings was normally distributed for females $(p=.080)$ but not for males $(p=.001)$. 
It was not normally distributed for younger $(p=.001)$ and older $(p=.000)$ speakers. It was not normally distributed for speakers with MS $(p=.011)$ and B.A. $(p=.000)$ education, although it was normally distributed for the other four levels of education: ES ( $p=.894)$, HS $(p=.274)$, A.A. $(p=.781)$, and Professional $(p=.229)$. Homogeneity of variance was violated for gender as assessed by Levene's Test for Equality of Variances $(p=.000)$, so the Welch statistic was required for the one-way ANOVA for gender. However, it was not violated for age $(p=.883)$ and education $(p=.193)$, where the Welch statistic was not required. However, for the sake of consistency, the Welch statistic was employed for all independent variables. Separate comparisons using the Least Significant Difference statistic were used for education to examine the significance of difference among the six educational levels.

There was statistically significant difference in the use of lexical borrowings between males and females, as determined by the one-way ANOVA test $(F(1,50)=16.561, p=.000)$, and confirmed by the Welch statistic $(F(1,30.796)=14.914, p=.001)$. The difference between younger and older speakers was not statistically significant in the use of lexical borrowings, as determined by the one-way ANOVA test $(F(1,50)=.326, p=.571)$ and confirmed by the Welch statistic $(F(1,49.316)=.328, p=.570)$. The difference between all six levels of education was statistically significant in the use of lexical borrowings, as determined by the Welch statistic $(F(5,18.829)=6.426, p=.001)$, although it was not significant in the one-way ANOVA test $(F(5,46)=2.023, p=.093)$. The Welch statistic result is confirmed by the Least Significant Difference post hoc test which revealed that the differences between speakers with professional education, on the one hand, and ES $(p=.004)$, A.A. $(p=.035)$, and B.A. $(p=.028)$ education, on the other, are statistically significant. There were no statistically significant differences among all other education levels.

6. Discussion and conclusion. In summary, males in general use more SA lexical borrowings with [q] than females. Age does not play a significant role in the use of these lexical borrowings. Education plays a significant role only in relation to professional education when compared to ES, A.A., and B.A. education. Education is not significant in relation to comparisons among all other levels of education including professional vs. MS and HS. Based on these findings, higher use of lexical borrowings could be considered a marker of male speech and of higher education in both male and female speech. Being a marker of higher education overrides being a marker of male speech, because females who are highly educated use lexical borrowings as much as males do. In other words, the gender effect diminishes when females are highly educated, and they are no longer differentiated from males. This situation could be analogized to social network markers (Milroy \& Milroy 1985). In Belfast, although women were associated with the raising of $/ \varepsilon /$ and men associated with the backing of /a/, the backing of /a/ became a social network marker for women who used it at higher rates than men. Likewise, the raising of $/ \varepsilon /$ became a social network marker for men who used it at higher rates than women.

Designating lexical borrowings as a marker of higher education that transcends being a marker of male speech highlights the importance of higher education for women, particularly rural women. Obtaining higher education will give rural women the chance to overcome the gender differences in society and the inferior feeling experienced within the city limits and to mesh well with their new urban environment in which competition is higher that it is in their home village.

It was observed that both younger and older men use more lexical borrowings than women. This indicates that the difference between men and women transcends the phonological level and 
extends to the lexical level which is associated with appealing topics of conversation and discussion which are in turn pertinent to whether the speaker is male or female, as these topics vary according to gender, education, and intended projected identity. On the phonological level, Habib (2010, 2011, 2014, 2016a,b, 2017) showed that in general males from rural origin (migrants to urban centers and non-migrants) use more rural consonants and vowels than females. In particular, males use the rural form [q] more than females who use the urban form [?] more (Habib 2010, 2016a,b). On the lexical level, it has been shown in this study that migrant males use more SA lexical borrowings with [q] than females. This higher use among males is believed to be related to the topics discussed by the speakers. A trickle-down effect of their higher use of the rural form [q] is not possible because lexical borrowings are pronounced the same by all speakers. During the unstructured interviews, it was observed that men choose to discuss manly topics that embody their role as the main bread winners and their masculine identity, such as politics, their profession, law, etc. Such topics entail the use of more lexical borrowings and jargons from SA, i.e. words that have no equivalent in CS. For example, Speaker \# 39 uses 68 SA lexical borrowings that constitute 24\% of his total use of [q] and [?] as variants of (q) and of SA [q] lexical borrowings. Most of his lexical borrowings are mostly pertinent to dentistry, his profession, and transfer of disease through malpractice or blood transfusion, e.g. taqwi:m 'orthodontia/orthodontics', luqa: $\hbar$ 'vaccination', taSqi:m 'sterilization', ?afri:qya 'Africa', Pintiqa:l 'transmission', etc. Likewise, Speaker \# 35 uses 71 lexical borrowings that are mostly related to medicine, his profession, e.g. muqi:m 'resident', qism liuru:q 'the burns department', Siqdi 'cyst', lsidi ddaraqiyyi 'the thyroid gland', etc.

The lower use of lexical borrowings by females highlight their stronger involvement in topics related to everyday life, home, children, play, cooking, cleaning, etc. Immersing in such topics embody their role as the main caregivers and their feminine identity. In other words, males' and females' linguistic choice of lexemes is dependent on the most common topics they converse about which are usually determined by the social and ideological classification of gender roles and expectations in society. Despite the elevated status of females in Syria (work- and educationwise), they are expected to be the main home keepers and children caregivers. Consequently, they are more preoccupied with these issues than with politics, professions, economics, etc. The general social attitude towards females is that they should not be involved in such high-level discussions, as they are perceived and expected to be reserved and agreeable regardless of their education and job status. Often, females are doubted if they express their political views and are at times asked to step aside as they are perceived as illiterate in this field, and thus they should maintain silence. Conversely, the lower expectations for males to run errands and do household chores give males significant advantage and opportunities to explore topics beyond the home and the children. This leads to having more time to meet with their male friends and discuss topics that are pertinent to them as males and that promote them among their friends and in public as well-informed masculine members of society. Hence, males and females are assigned specific social roles according to which they should react socially and linguistically. In other words, the use of lexical borrowings can highlight one's gender identity based on the social perception and gender role expectations of males and females.

It is worth noting that having differences in the rate of use of lexical borrowings between males and females does not mean that females are incapable of employing the same lexical borrowings used by males. In fact, the use of similar lexical borrowings is evidenced in the speech of many females. For example, Speaker \# 41, who holds a master's degree in architectural engineering and teaches at the university level, uses 32 lexical borrowings that 
constitute 19\% of her total use of the variants [q] and [?] and lexical borrowings with [q], e.g. qubu:l 'admission', lmulhaq ssaqa:fe: 'the cultural attaché', etc. The same word qubu:l 'admission' occurs also in the speech of the male Speakers \# 35 and 8. There are many other examples of lexical borrowings that occur in both male and female speech, e.g. qara:r 'decision', saqa:fi 'education, culture', siqa 'trust', etc. Hence, the difference could be associated merely with the frequency of occurrence of lexical borrowings in the speech of males and females, younger and older speakers, and highly and less educated speakers because lexical borrowings are expected to be pronounced the same by all speakers including urban speakers. In this study, only gender and education emerged as significant influential social factors in the use of lexical borrowings. Since frequency of use of lexical borrowings, despite their similar pronunciation across the board, can be affected by external social factors, one can assume that every linguistic aspect of our lives is the byproduct of some type of social interaction, situation, topic, and/or interference that prompt(s) us to adopt it or not and to use it frequently or not in our speech.

In conclusion, lexical borrowings can socially tell a great deal about speakers. They can reveal whether a person is highly educated or belongs to a specific gender, although the latter distinction is weaker than the former due to the similarity between highly educated males and females. What is most striking is that while many of the rural migrants in this study are shifting towards the use of the urban form [?] (Habib 2008, 2010), they are capable of distinguishing SA lexical borrowings and retaining the [q] in these words. Achieving equilibrium between sounding urbane and prestigious by using [?] and maintaining the high status of SA by retaining the [q] in SA borrowings underscores their complex linguistic sociocognitive and adaptive capabilities.

\section{References}

Abdel-Jawad, Hassan Rashid. 1981. Phonological and Social Variation in Arabic in Amman. Ph.D. dissertation, University of Pennsylvania.

Abu-Haidar, Farida. 1992. Shifting boundaries: The effect of MSA on dialect convergence in Baghdad. In Ellen Broselow, Mushira Eid, and John McCarthy (eds.), Perspectives on Arabic Linguistics IV. 91-106. [Current Issues in Linguistic Theory, 85]. Amsterdam: John Benjamins.

Al-Ani, Salman H. 1976. The development and distribution of the Arabic 'qaf' in Iraq. In Salman H. Al-Ani (ed.), Readings in Arabic Linguistics (1978). 103-110. Bloomington, Indiana: Indiana University Linguistics Club.

Blanc, Haim. 1964. Communal Dialects in Baghdad. Cambridge, MA: Harvard University Press.

Bowden, John. 2005. Lexical borrowing. In Philipp Strazny (ed.), Encyclopedia of linguistics. 620-622. New York: Taylor \& Francis.

Boyd, Sally, Paula Andersson, \& Christina Thornell. 1997. Patterns of incorporation of lexemes in language contact: Language typology or sociolinguistics? In Gregory R. Guy, Crawford Feagin, Deborah Schiffrin, and John Baugh (eds.), Towards a Social Science: Papers in Honor of William Labov. 259-284. Amsterdam: John Benjamins.

Daher, Jamil. 1998. Linguistic Variation in Damascus Arabic: A Quantitative Analysis of Men's and Women's Speech. Ph.D. dissertation, New York University.

Daulton, Frank E. 2012. Lexical borrowing. In The Encyclopedia of Applied Linguistics. 33083313. Chichester, West Sussex, UK: Wiley-Blackwell.

Diem, Werner. 1974. Hochsprache und Dialekt im Arabischen, Untersuchungen zur heutigen arabischen Zweisprachigkeit, Weisbaden: Franz Steiner Verlag. 
Eckert, Penelope. 1988. Adolescent social structure and spread of linguistic change. Language in Society 17, 183-207.

Ferguson, Charles A. 1959. Diglossia. Word 15. 325-340.

Garbell, Irene. 1958. Remarks on the historical phonology of an Eastern Mediterranean Arabic dialect. Word 14. 303-337.

Habib, Rania. 2005. The role of social factors, lexical borrowing and speech accommodation in the variation of [q] and [?] in the colloquial Arabic of rural migrant families in Hims, Syria. M.A. thesis, University of Florida.

Habib, Rania. 2008. New model for analyzing sociolinguistic variation: The interaction of social and linguistic constraints. Ph.D. dissertation, University of Florida.

Habib, Rania. 2010. Rural Migration and Language Variation in Hims, Syria. SKY Journal of Linguistics 23. 61-99.

Habib, Rania. 2011. Meaningful variation and bidirectional change in rural child and adolescent language. University of Pennsylvania Working Papers in Linguistics 17(2). 81-90. Article 10.

Habib, Rania. 2014. Vowel variation and reverse acquisition in rural Syrian child and adolescent language. Language Variation and Change 26(1). 45-75.

Habib, Rania. 2016a. Bidirectional linguistic change in rural child and adolescent language in Syria. Dialectologia 16. 117-141.

Habib, Rania. 2016b. Identity, ideology, and attitude in Syrian rural child and adolescent speech. Linguistic Variation 16(1). 34-67.

Habib, Rania. 2017. Parents and their children's variable language: Is it acquisition or more? Journal of Child Language 44(3). 628-649.

Haeri, Niloofar. 1991. Sociolinguistic variation in Cairene Arabic: Palatalization and the qaf in the speech of men and women. Ph.D. dissertation, University of Pennsylvania.

Haspelmath, Martin. 2009. Lexical borrowing: Concepts and issues. In Martin Haspelmath and Uri Tadmor (eds.), Loanwords in the World's Languages: A Comparative Handbook. 3554. Berlin: de Gruyter.

Haugen, Einer. 1950. The analysis of linguistic borrowing. Language 26. 210-231.

Haugen, Einar \& Marianne Mithun. 2003. Borrowing. In William J. Frawley (ed.), International Encyclopedia of Linguistics. 242-249. Oxford: Oxford University Press.

Holes, Clive. 1995. Modern Arabic: Structures, Functions and Varieties. London: Longman.

Mesthrie, Rajend \& William L. Leap. 2000. Language contact 1: Maintenance, shift and death. In Rajend Mesthrie, Joan Swann, Andrea Deumert, and William L. Leap (eds.), Introducing Sociolinguistics. 248-278. Amsterdam/Philadelphia: John Benjamins.

Milroy, James \& Lesley Milroy. 1985. Linguistic change, social network and speaker innovation. Journal of Linguistics 21. 339-384.

Mol, Mark van. 2003. Variation in Modern Standard Arabic in Radio News Broadcasts: A Synchronic Descriptive Investigation into the Use of Complementary Particles.

Leuven/Dudley, MA: Peeters and Departement Oostere Studies.

Owens, Jonathan \& Raslan Bani-Yasin. 1991. Spoken Arabic and Language Mixture. In Pierre Larcher (ed.), De la grammaire de l'arabe aux grammaires des arabes. 17-33. [Bulletin d'études orientales, T. 43]. Damas: Institut Francais De Damas.

Palva, Heikki. 1969. Notes on classicisation in Modem Colloquial Arabic. Studia Orientalia 40(3). 3-41. 
Poplack, Shana. 1997. The sociolinguistic dynamics of apparent convergence. In Gregory R. Guy, Crawford Feagin, Deborah Schiffrin, and John Baugh (eds.), Towards a Social Science: Papers in Honor of William Labov. 285-309. Amsterdam: John Benjamins.

Poplack, Shana, David Sankoff \& Christopher Miller. 1988. The social correlates and linguistic processes of lexical borrowing and assimilation. Linguistics 26. 47-104.

Weinreich, Uriel. 1974. Language in Contact. The Hague: Mouton Publishers.

Wilmsen, David. 1995. The word-play's the thing: Educated spoken Arabic in a theatrical community in Cairo. Ph.D. dissertation, University of Michigan. 